\title{
Characterization of a Bipartite Medial Cuneiform: Micro-CT and Anatomical Study
}

\author{
Caracterización de un Cuneiforme Medial Bipartito: Micro-CT y estudio anatómico
}

\author{
Miki Dalmau-Pastor ${ }^{1,2,3}$; Jordi Vega ${ }^{1,3,4}$; Alicia Baltasar-Sánchez ${ }^{5}$;otfi Slimani ${ }^{6}$; \\ Jorge Belinha ${ }^{7}$; Ángel González Sistal ${ }^{5}$ \& M. C. Manzanares ${ }^{1}$
}

DALMAU-PASTOR, M.; VEGA, J.; BALTASAR-SÁNCHEZ, A.; SLIMANI, L.; BELINHA, J.; GONZÁLEZ S. Á. \& MANZANARES, M. C. Characterization of a bipartite medial cuneiform: Micro-CT and anatomical study. Int. J. Morphol., 36(4):13721377, 2018.

SUMMARY: A bipartite medial cuneiform is an anatomical variant consisting in a horizontal division of the bone. Previous descriptions of the joint type, obtained from archaeological material or clinical reports, are unclear. This study was conducted in a fresh-frozen left foot, which allowed studying the morphology of the ligaments after anatomical dissection. In addition a Micro-CT analysis was performed to elucidate the osseous structure supporting the articular surfaces. A complex ligamentous system was found between the two halves of the bipartite medial cuneiform. Two articular surfaces were observed between the two components. Hyaline cartilage was observed at the posterior surface, while fibrous tissue was found at the anterior surface. Micro-CT analysis revealed different osseous structures for each articular surface, thus proving the existence of two joint types. The finding of a bipartite medial cuneiform in a fresh-frozen specimen allowed us to perform an analysis of the soft-tissues and articular surfaces that shows the presence of hyaline cartilage and articular ligaments in the diarthrodial joint as well as the fibrous component of the synfibrosis. Micro-CT analysis further reinforces our morphological findings. Our results prove that two different joint types exist, which could help explaining the disparity of descriptions in the literature.

KEY WORDS: Anatomy; Dissection; Foot; Tarsal bones; bipartite medial cuneiform.

\section{INTRODUCTION}

A Bipartite Medial Cuneiform (BMC) is a well-known anatomical variant affecting the medial part of the foot. This condition was first described in 1757 as being characterized by a horizontal bipartition of the medial cuneiform, which is divided in two parts, one dorsal and another plantar. A recent meta-analysis has reported numerous cases, mostly from anthropological material (Burnett \& Case, 2011).

However, most of the descriptions reported are controversial with respect to the type of articulation present between the two halves of the bipartite bone. Reported articulations include synchondrosis, syndesmosis (O’Neal et al., 1995; Azurza \& Sakellariou, 2001; Chiodo et al., 2002) and "some combination of both" (Burnett \& Case).

Moreover, it is thought that this anatomical variation can alter foot biomechanics (Chiodo et al.; Bismil et al., 2005; Fulwadhva \& Parker, 2007) causing clinical symptoms like dorsomedial foot pain, swelling and tenderness. When a midfoot pain is present, the most common radiological diagnosis is a fracture or a tarsal coalition, while a bipartite medial cuneiform is less frequent, but it has to be considered in the differential diagnosis of midfoot pain (Bismil et al.).

\footnotetext{
${ }^{1}$ Human Anatomy Unit, Department of Pathology and Experimental Therapeutics, School of Medicine. University of Barcelona, C/ Feixa Llarga, s/n, 09806, Hospitalet de Llobregat, Barcelona, Spain.

${ }^{2}$ Faculty of Health Sciences at Manresa, University of Vic-Central University of Catalonia, Manresa, Barcelona, Spain.

${ }^{3}$ GRECMIP (Groupe de Recherche et d'Etude en Chirurgie Mini-Invasive du Pied), Merignac, France.

${ }^{4}$ Foot and Ankle Unit, Hospital Quirón Barcelona, Barcelona, Spain.

${ }^{5}$ Medical Imaging Lab, Physiological Sciences II, School of Medicine. University of Barcelona, C/ Feixa Llarga, s/n, 09806, Hospitalet de Llobregat, Barcelona, Spain.

${ }^{6}$ EA 2496, Laboratory Orofacial Pathologies, Imaging and Biotherapies, Dental school \& Life Imaging Facility of Paris Descartes University (Plateforme Imageries du Vivant - PIV), Sorbonne Paris Cité, France.

${ }^{7}$ Faculty of Engineering of the University of Porto, Department of Mechanical Engineering. Institute of Mechanical Engineering and Industrial Management, Portugal
} 
This paper reports a complete anatomical and microCT study of a non-archaeological sample; this allowed the study of a previously undescribed ligamentous system joining the two halves of the BMC. Furthermore, the radiological and Micro-CT exploration of the sample was carried out in physiological position. Since the bipartition of the cuneiform was initially diagnosed by radiology, the Micro-CT study was carried out to elucidate the osseous structure and the articular surfaces existent between the two halves of the bipartite.

\section{MATERIAL AND METHOD}

During realization of imaging tests on fresh-frozen cadaveric specimens for a study, a bipartite medial cuneiform was identified in a 77 year-old man left foot. The foot (a below-the-knee specimen) was excluded from the original study, and a specific study of this anatomical variant was performed. The specimen studied did not present any apparent deformity or signs of previous surgical intervention. The specimen was under the custody of the Cadaver Donors Service and Dissection Room of the Faculty of Medicine, University of Barcelona, Spain.

Anatomical study: When all imaging tests were checked to assure proper identification of the bipartite medial cuneiform by an experienced radiologist, a dissection of the foot was carried out in order to observe the morphology of the bone and the joints, and to obtain high-resolution images to compare radiologic images with real anatomy (Camera Nikon D800, Objective Nikon Micro Nikkor 105mm, Nikon Corp., Tokyo, Japan).

Dissection of the medial side of the foot was executed until an osteo-articular view of the medial tarsometatarsal joint and medial cuneo-navicular joint was exposed. Tibialis anterior tendon and ligaments were preserved and photographs taken. After this, complete disarticulation of the foot was performed.

Bones were immersed in $\mathrm{H} 2 \mathrm{O} 230 \%$ solution (Hydrogen Peroxide $30 \%$ w/v stabilized PRS, Panreac, Barcelona, Spain) diluted at $15 \%$ with hot water, in order to remove all soft tissues and thus permit the analysis of the articular surfaces and bone relations. During this process, careful preservation of hyaline cartilage was ensured and bones were constantly revised to avoid their damage. Once all soft tissue was removed with periostotome, bones were submerged in Embalming mixture (Panreac Embalming Mixture QP, Panreac, Barcelona, Spain) diluted at $3 \%$ with water for final museum preservation of the specimen.
Micro-CT study. The specimen under study was scanned using a high-resolution X-ray Micro-CT device (Quantum FX Caliper, Life Sciences, Perkin Elmer, Waltham, MA) hosted by the Micro-CT platform, EA2496 \& Life Imaging Facility of Paris Descartes University (PIV), Montrouge, France. Samples were scanned with a field of view (FOV) of $10 \mathrm{~mm}$ diameter and three-dimensional acquisitions were performed using an isotropic voxel size of 20x20x20 mm3 (90 kV, $160 \mathrm{~mA}, 180 \mathrm{~s})$. Full 3D high-resolution raw data was obtained by rotating both the X-ray source and the flat panel detector $360^{\circ}$ around the sample, with a rotation step of $0.1^{\circ}$ (scanning time: $3 \mathrm{~min}$ ). The corresponding 3,600 image projections were then automatically reconstructed (RigakuSW software, Caliper) into a DICOM stack of 512 files using standard back-projection techniques (reconstruction time: 1 minute). For each sample, the microCT volumetric acquisition provided a stack of 512 cross sections. The multiplanar reconstruction tools allowed greylevel images to be displayed with an axial orientation. The lowest grey/dark pixels correspond to empty spaces and the highest grey/bright pixels to the densest/mineralized tissues. Bone volume was measured using the open-source OsiriX imaging software (v3.7.1, distributed under LGPL license, Dr A. Rosset, Geneva, Switzerland) from stack of 2D images. Binary thresholds were applied to isolate the osseous tissue from the surrounding tissue.

The volume scanned by micro-CT comprised the entire bipartite cuneiform bone. The 2D images were processed and characterized with a computerized method developed by our group. The workflow of image processing analysis includes the following steps: (1) image acquisition, (2) filtering for image enhancement, (3) selection of a region of interest (ROI), (4) filtering for noise reduction, (5) morphometric analysis and (6) statistical analysis to distinguish between groups.

The parameters assessed were: trabecular thickness (Tb.th) and trabecular separation (Tb.sp) in 2D. A 3D calculation of the trabecular bone volume fraction (BV/TV) was obtained in order to ascertain the structural strength supporting each articular surface or bone surface density (\%). All those values were calculated using bone area and bone perimeter values, based in the guidelines of the American Society of Bone and Mineral Research (Dempster et al., 2013).

\section{RESULTS}

Anatomical study: When compared with a normal specimen, the bipartite cuneiform showed only a slightly larger size, with no further anatomical differences besides 
the presence of the articulation between its two osseous components (Fig. 1).

The plantar piece had a rectangular cuboid shape and a larger size than the dorsal piece of the bipartite bone. The following anatomical landmarks were present: two tubercles, one on the proximal and plantar side, for tibialis posterior tendon insertion, and one inferior anterolateral small tubercle for peroneus longus tendon insertion. Moreover, a small impression was found at the medial side, where tibialis anterior tendon inserted; a small ridge for the insertion of the interosseous ligament for the intermediate cuneiform was present at its anterolateral corner. Finally, a roughened surface was located at the anterior part of its dorsal side, where the fibrous tissue joining the two pieces is situated.

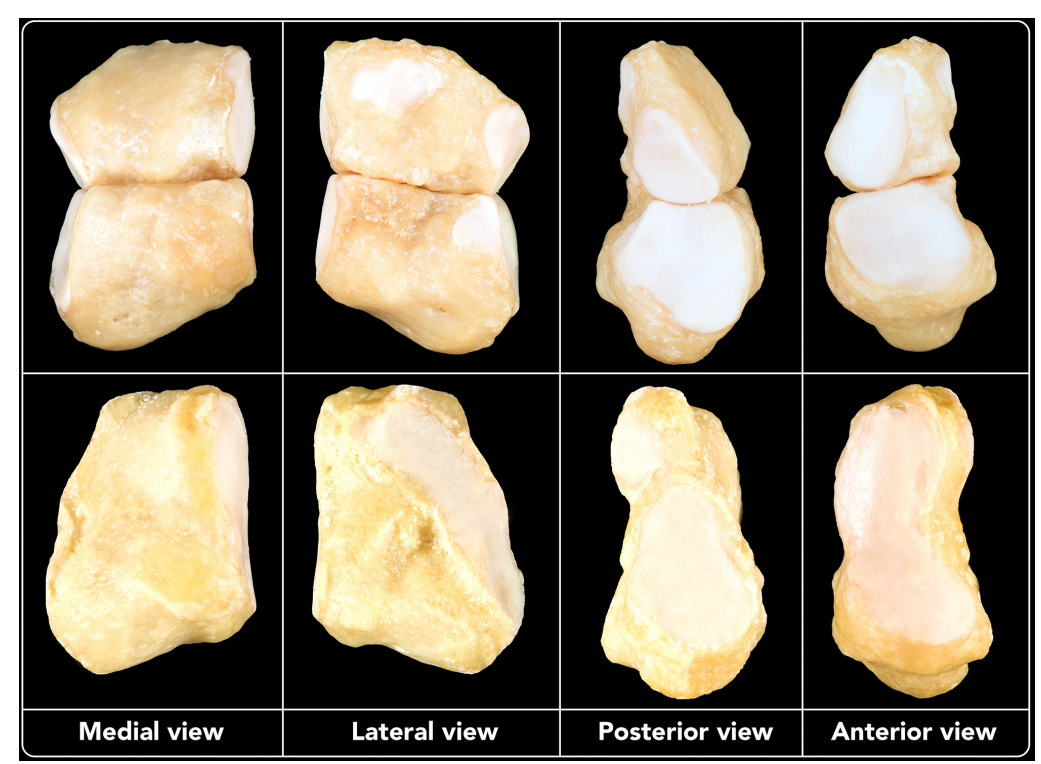

Fig. 1. Morphologic comparison of a bipartite medial cuneiform (top line) and a normal medial cuneiform (bottom line).

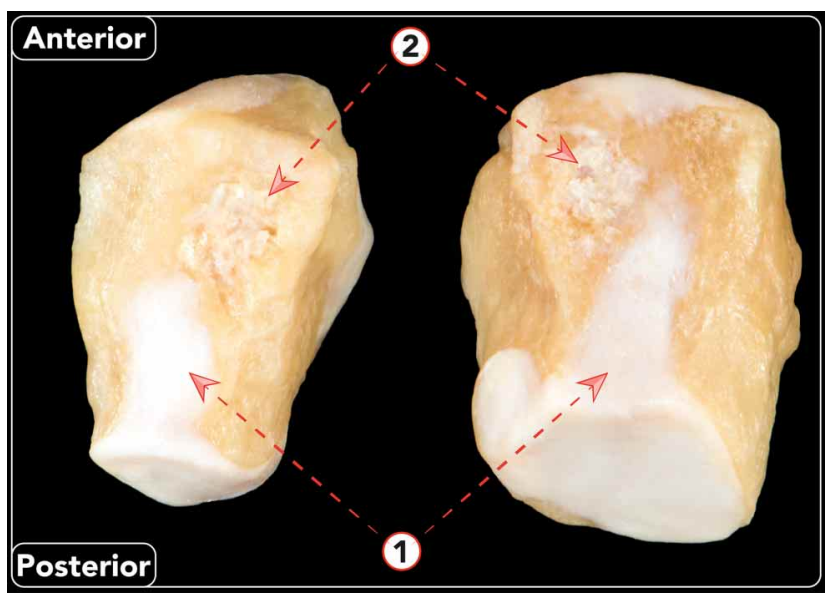

Fig. 2. View of the articular surfaces of the bipartite medial cuneiform. 1. Hyaline cartilage articular surface (diarthrodial joint). 2. Fibrous tissue articular surface (synfibrosis)
As for the dorsal piece, it was smaller when compared with the plantar piece. It had a triangular pyramid shape with plantarmedial base and dorsolateral vertex, larger anteriorly than posteriorly. As in the plantar piece, a ridge was present at the anterolateral part of the dorsal piece, where the interosseus ligament for the intermediate cuneiform was inserted. A roughened surface located at the anterior part of its plantar side is where the fibrous tissue joining the two pieces was found.

When analysing the articular surfaces between the plantar and dorsal pieces, we observed that the posterior half was formed by a smooth triangular surface of hyaline cartilage, continuous with the articular surfaces for the navicular bone. On the other hand, the anterior half of the bipartite articulation showed an irregular shape, with a rough surface with fibrous tissue uniting the two pieces (Fig. 2). From a lateral view, on the proximal part of the lateral facets of both pieces of the BMC, a small articular surface was visible as a prolongation of the posterior articular surface. These surfaces were for articulating with the intermediate cuneiform, which, in contrast, showed no articular surface. The dorsal piece had an extra articular surface at the mid part, also for the intermediate cuneiform.

When the two fragments of the BMC are put together, they form articular surfaces for articulating with the navicular bone, first and second metatarsals and intermediate cuneiform, which do not greatly differ from the normal morphology. The only difference is the horizontal division of the articular surface because of the bipartition. The articular facets of the navicular, first and second metatarsals and intermediate cuneiform carried also a horizontal division that made them congruent with the BMC (Fig. 3).

As for the ligaments, at the medial side five ligaments were noted, surrounded by a thin joint capsule nearly indistinguishable of the surrounding subcutaneous fatty tissue. Two ligaments originated from the navicular, one directed to the dorsal and one to the plantar piece of the $\mathrm{BMC}$. The dorsal and the plantar pieces were united to the first metatarsal by two ligaments, one for each piece. A multifascicular ligament was found to be the responsible of the union between the two pieces of the BMC. It was inserted obliquely from proximal to distal and anterior to posterior (Fig. 4). In addition, the insertion of the tibialis anterior tendon at the distal part of the plantar piece and base of the first metatarsal acted as a stabilizer between these two bones. 


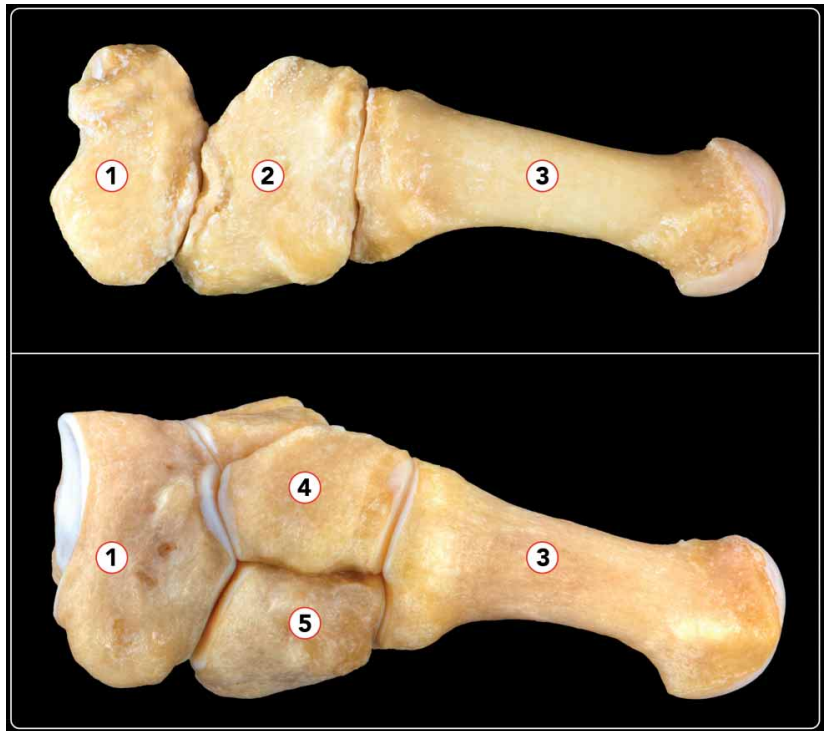

Fig. 3. Morphologic comparison of the bones that articulate with a normal medial cuneiform (above) and with a bipartite medial cuneiform (bottom). 1. Navicular bone. 2. Normal medial cuneiform. 3. First metatarsal. 4. Dorsal part of the bipartite medial cuneiform. 5. Plantar part of the bipartite medial cuneiform.

The dissection of the anatomical sample revealed 4 ligaments in the dorsal view. One from the navicular to the dorsal piece of the BMC, and three ligaments originated at the dorsal piece of the $\mathrm{BMC}$ and attached to the intermediate cuneiform, the base of the second metatarsal bone and the base of the first metatarsal bone.

4 different ligaments were observed at the lateral side, being these interosseous ligaments: 2 originated at the dorsal piece of the BMC and inserted at the second metatarsal and intermediate cuneiform. 2 originated at the plantar piece of the $\mathrm{BMC}$ and inserted at the base of the second and third metatarsals.

The existence of hyaline cartilage and a ligamentous system joining the two pieces corroborates the existence of at least a diarthrodial articulation.

However, when the articulation between the two halves of the BMC was opened, fibrous tissue connected the two pieces (Fig. 2); it was located at the rough distal part of the articular surfaces. No other soft-tissue interosseous structures were noted. This finding corroborates the existence of a synfibrosis between the two pieces.

Micro-CT study: 2D micro CT image in an axial plane reveals the bipartition of the medial cuneiform bone. Two articular surfaces, supported by different trabecular structures are evident, showing two different articulations constituting the union between the two pieces. The proximal one presents a smooth, well corticated osseous articular surface, with clear margins and a continuous supporting trabecular structure. This is coherent with the presence of the articular cartilage and ligaments evident in Figures 2 and 4. On the other hand the microstructure of the rough surface covered by fibrous tissue situated in the distal part of the articular surfaces shows a cortical of variable thickness and an irregular surface supported by a less dense trabecular meshwork.

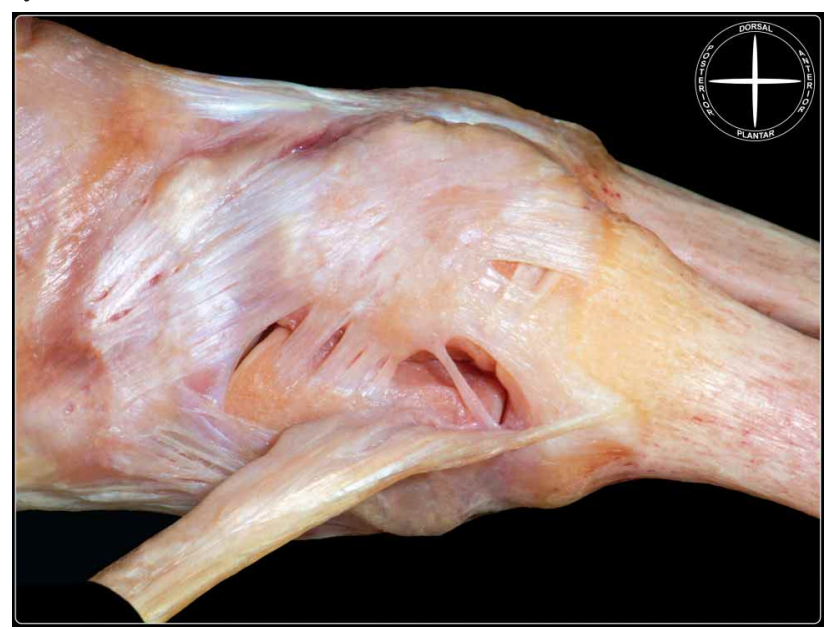

Fig. 4. Osteoarticular dissection of the medial side of the foot demonstrating the ligamentous structures that join the two halves of the bipartite medial cuneiform with first metatarsal, navicular and between them. Tibialis anterior tendon is retracted plantarly.

When comparing the two articulations, observed both in antero-posterior and medio-lateral view, the posterior has the anatomical characteristics of a diarthrosis and presents continuous, regular, dense articular cortical surfaces in the two pieces. These articular surfaces are supported by a robust mesh of densely interconnected trabeculae, continuous with the trabecular structure of the two cuneiform components. The anterior articular surface shows irregular cortical surfaces in both pieces, with interdented pits and spikes, supported by thinner and less connected trabeculae, which is coherent with the previous descriptions of this articulation as a synfibrosis (Fig. 5).

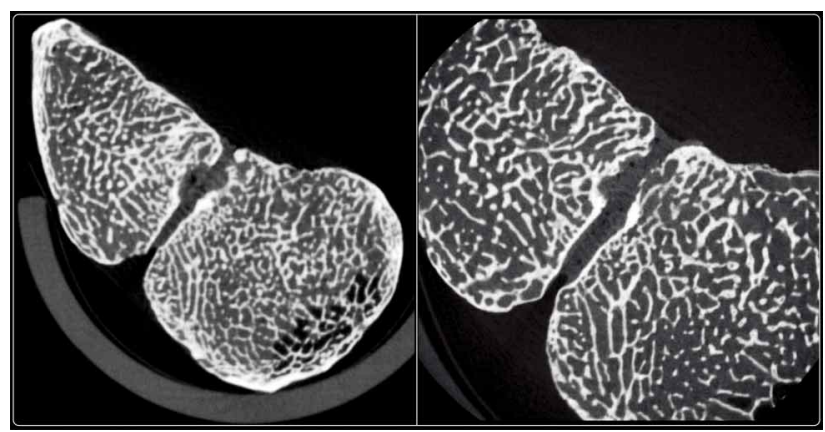

Fig. 5. Frontal (left) and side (right) view of the Micro-CT imaging of the bipartite medial cuneiform showing the osseous structure of the two articular surfaces between the two halves of the bipartite medial cuneiform. 
Table I. Morphometric image parameters for each articulation of BMC

\begin{tabular}{lccccccc}
\hline & Tb.sp Mean & Tb.sp StdDev & Tb.sp Max & Tb.th Mean & Tb.th StdDev & Tb.th Max & BV/TV (\%) \\
\hline BMC_1 & 0.881 & 0.512 & 2.246 & 0.459 & 0.180 & 0.973 & 0.102 \\
BMC_2 & 0.654 & 0.252 & 1.219 & 0.379 & 0.141 & 0.933 & 0.056 \\
\hline
\end{tabular}

BMC_1: Synfibrosis; BMC_2:Diarthrosis. Tb.sp: Trabecular separation; Tb.th: Trabecular thickness; BV/TV: Bone surface density (\%).

The numeric value of the trabecular thickness, trabecular separation and the trabecular bone volume fraction parameters obtained in these two articular surfaces is clearly different and further reinforces the descriptive data of each type of joint (Table I).

\section{DISCUSSION}

Bipartite Medial Cuneiform (BMC) represents one of the oldest and the most frequently observed example of such condition amongst tarsal bones (Jashashvili et al., 2010; Burnett \& Case). It affects the medial part of the foot and is characterized by a horizontal bipartition of the medial cuneiform that, despite the fact of being a congenital condition, has not a demonstrated heritability.

Although the majority of the reported bipartite medial cuneiforms come from archaeological material (Kjellström, 2004; Jashashvili et al.), the use of magnetic resonance imaging and computed tomography in clinical diagnostics of midfoot trauma and pathology has recently resulted in reports of clinical cases (Sener, 1999; Azurza \& Sakellariou; Chiodo et al.; Bismil et al.; Fulwadhva \& Parker; Elias et al., 2008; Eves et al., 2014) with only a histological report (O'Neal et al.). From the largest series studied, an incidence between 0.27 and 0.31 $\%$ has been reported, being a variation most frequently bilateral (Burnett \& Case).

According to Barclay (1932), bipartition can be partial, in which a transverse groove or two separated grooves divide in two parts the articular surface, or complete in which the bone is divided transversely in two elements, dorsal and plantar as in our results. Invariably this division is horizontal (Barclay; Barlow, 1942; Anderson, 1987).

In complete bipartitions, the articulation between the two osseous components is described as a synchondrosis, a syndesmosis or a "combination of both" (O'Neal et al.; Azurza \& Sakellariou; Chiodo et al.; Burnett \& Case). Recently, clinical reports of the bipartite cuneiform halves being united by an arthrodial joint (Elias et al.) confirmed previous descriptions by Barlow about the presence of a cartilaginous articular surface such as the one visible in Figure 2. Other reports describe that the articulation of both parts reveals pitting or irregularities of the articular surfaces, similar to the ones visible in skull sutures (Kjellström; Burnett \& Case), the morphological differences between the articular surfaces being attributed to a partial ossification of the synchondrosis or syndesmosis (Anderson; O'Neal et al.).

In partial bipartitions, bones are usually united by a central ossified bridge (Dastugue \& Gervais, 1992). In some cases, the two pieces eventually coalesce through ossification (synostosis), but maintaining two separate distal facets for articulating with first metatarsal (Friedl, 1934). Medial cuneiforms with two distal articular facets and with a slight cleft or crease between the otherwise conjoined plantar and dorsal parts are reported as examples of partial bipartitions (Barclay; Barlow; Dastugue \& Gervais).

The type of articulation uniting the two osseous elements is very controversial. The authors reviewed by Burnett use the term "synchondrosis" to describe the presence of cartilage in the articular space, unrelated to the type of articulation established between the two osseous elements. However, a synchondrosis is a synarthrosis, arranged as a juncture without a cavity, connected by means of a cartilage. Thus the term synchondrosis should be considered as inappropriate to describe an articulation with synovial cavity (Kachlik et al., 2015), such as the case we are describing.

Our results clearly show that two different articulations unite the parts of the bipartite cuneiform: the presence of cartilage is due to its participation in the diarthrodial joint, while the other articulation is a synfibrosis, a synarthrosis that could experience closure due to membranous ossification, process in which no cartilage is involved (Manzanares et al., 1988). Our finding of two joint types uniting the two halves of the BMC could explain the variety of descriptions of this joint in the clinical reports (Sener; Azurza \& Sakellariou; Chiodo et al.; Bismil et al.; Fulwadhva \& Parker; Eves et al.).

The case described by Elias et al. in which the lateral portion of the articulation, a diarthrosis, had developed degenerative arthritis, reinforcesour view that the articulation of the two halves of a bipartite medial cuneiform is constituted by two different articulations. Only a diarthrosis, with a synovial membrane situated within a complete capsule such as the one we have described, can be altered in the reported manner. However, both in our results, in their report and in many others (Kjellström; Jashashvili et al.), another articulation with the morphological characteristics of a 
synfibrosis is described, this being the second articulation that unites the two components of the bipartite cuneiform.

This study, performed on fresh anatomic material, has permitted to describe the anatomical characteristics of the joint present between the two halves of a BMC. On one hand, the presence of a ligamentous system and a joint capsule proves the existence of a diarthrodial joint. On the other hand, the presence of a fibrous tissue connecting two irregular articular surfaces is characteristic of a synfibrosis. Finally, the MicroCT results have shown that the osseous structures supporting each articular surface correspond to two joint types, with different biomechanical characteristics (Marques et al., 2018).

ACKNOWLEDGEMENTS. The authors with to thank the donor, by his generous contribution to Science, and Dr. Anna Kjellström from Stockholm University for providing one of the papers cited in this publication. Part of the anatomical descriptions was carried out by our colleague Prof Pau Golanó Álvarez (1964-2014), to whom this paper is dedicated.

DALMAU-PASTOR, M.; VEGA, J.; BALTASAR-SÁNCHEZ, A.; SLIMANI, L.; BELINHA, J.; GONZÁLEZ S. Á. \& MANZANARES, M. C. Caracterización de un Cuneiforme Medial Bipartito: Micro-CT y estudio anatómico. Int. J. Morphol., 36(4):1372-1377, 2018.

RESUMEN: El cuneiforme medial bipartito es una variación anatómica que consiste en una división horizontal del hueso. Las descripciones previas del tipo de articulación entre los dos fragmentos, obtenidas de material arqueológico o de reportes clínicos, son heterogéneas. Este estudio se llevó a cabo en un pie izquierdo disecado en fresco, lo que permitió analizar la morfología de los ligamentos. Adicionalmente se llevó a cabo un análisis con Micro-CT a fin de aclarar la estructura ósea de soporte de las superficies articulares. Un sistema ligamentoso complejo une las dos mitades del cuneiforme medial bipartito. Se observaron dos superficies articulares uniendo ambos componentes. En la superficie posterior se encontró cartílago hialino, en tanto que la superficie anterior presentaba tejido fibroso uniendo las superficies articulares. El análisis por Micro-CT mostró que la estructura ósea de soporte de cada una de las superficies articulares es diferente, confirmando la existencia de dos articulaciones distintas. El hallazgo de un cuneiforme medial bipartito en un espécimen fresco ha permitido el estudio de las partes blandas y superficies articulares, demostrando la presencia simultánea del cartílago hialino y los ligamentos propios de una diartrosis y del tejido fibroso propio de una sinfibrosis, lo que ha sido posteriormente corroborado por el análisis por Micro-CT. Nuestros resultados demuestran por tanto que se trata de dos articulaciones distintas, lo cual explica la disparidad de las descripciones en la literatura.

PALABRAS ClAVE: Anatomía; Disección; Pie; Huesos tarsales; cuneiforme medial bipartito.

\section{REFERENCES}

Anderson, T. A medieval biparte cuneiform I with attempted unilateral fusion. Ossa, 13:39-48, 1987.
Azurza, K. \& Sakellariou, A. 'Ostoesynthesis' of a symptomatic bipartite medial cuneiform. Foot Ankle Int., 22(6):499-501, 2001.

Barclay, M. A case of duplication of the internal cuneiform bone of the foot (Cuneiforme bipartitum). J. Anat., 67(Pt. 1):175-7, 1932.

Barlow, T. E. Os cuneiforme 1 bipartitum. Am. J. Phys. Anthropol., 29(1):95$111,1942$.

Bismil, Q.; Foster, P. A. L.; Venkateswaran, B. \& Shanker, J. Symptomatic bipartite medial cuneiform after injury: a case report. Foot Ankle Surg., 11(1):55-8, 2005.

Burnett, S. E. \& Case, D. T. Bipartite medial cuneiform: new frequencies from skeletal collections and a meta-analysis of previous cases. Homo, 62(2):10925, 2011.

Chiodo, C. P.; Parentis, M. A. \& Myerson, M. S. Symptomatic bipartite medial cuneiform in an adult athlete: a case report. Foot Ankle Int., 23(4):348-51, 2002.

Dastugue, J. \& Gervais, V. Paléopathologie du Squelette Humain. Paris, Société Nouvelle Des Éditions Boubée, 1992.

Dempster, D. W.; Compston, J. E.; Drezner, M. K.; Glorieux, F. H.; Kanis, J. A.; Malluche, H.; Meunier, P. J.; Ott, S. M.; Recker, R. R. \& Parfitt, A. M. Standardized nomenclature, symbols, and units for bone histomorphometry: a 2012 update of the report of the ASBMR Histomorphometry Nomenclature Committee. J. Bone Miner. Res., 28(1):2-17, 2013.

Elias, I.; Dheer, S.; Zoga, A. C.; Raikin, S. M. \& Morrison, W. B. Magnetic resonance imaging findings in bipartite medial cuneiform - a potential pitfall in diagnosis of midfoot injuries: a case series. J. Med. Case Rep., 2:272, 2008.

Eves, T. B.; Ahmad, M. A. \& Oddy, M. J. Sports injury to a bipartite medial cuneiform in a child. J. Foot Ankle Surg., 53(2):232-4, 2014.

Friedl, E. Zweigeteiltes 1. Keilbein im Kindesalter. Roentgenprax Diag. Roent. Rad. Lichttherap., 6:194-4, 1934.

Fulwadhva, U. \& Parker, R. J. Symptomatic bipartite medial cuneiform. Appl. Radiol., 3, 2007. Available from: https://appliedradiology.com/articles/ symptomatic-bipartite-medial-cuneiform

Jashashvili, T.; Ponce de León, M. S.; Lordkipanidze, D. \& Zollikofer, C. P. First evidence of a bipartite medial cuneiform in the hominin fossil record: a case report from the Early Pleistocene site of Dmanisi. J. Anat., 216(6):705-16, 2010.

Kachlik, D.; Musil, V. \& Baca, V. Terminologia Anatomica after 17 years: inconsistencies, mistakes and new proposals. Ann. Anat., 201:8-16, 2015.

Kjellström, A. A case study of os cuneiforme mediale bipartum from Sigtuna, Sweden. Int. J. Osteoarchaeol., 14(6):475-80, 2004.

Manzanares, M. C.; Goret-Nicaise, M. \& Dhem, A. Metopic sutural closure in the human skull. J. Anat., 161:203-15, 1988.

Marques, M.; Belinha, J.; Oliveira, A. F.; Manzanares Céspedes, M. C. \& Natal Jorge, R. M. A multiscale homogenization procedure combining the fabric tensor with a natural neighbour meshless method. Eng. Anal. Bound. Elem., 2018. doi.org/10.1016/j.enganabound.2018.05.007 (In Press).

O’Neal, M. L.; Ganey, T. M. \& Ogden, J. A. Fracture of a bipartite medial cuneiform synchondrosis. Foot Ankle Int., 16(1):37-40, 1995.

Sener, R. N. Bilateral extra tarsal bones in Rubinstein-Taybi syndrome: the fourth cuneiform bones. Eur. Radiol., 9(3):483-4, 1999.

\section{Corresponding author:}

Miki Dalmau-Pastor

Human Anatomy Unit

Department of Pathology and Experimental Therapeutics

School of Medicine.

University of Barcelona,

Barcelona

SPAIN

Email: mikeldalmau@ub.edu 